\title{
НЕКОТОРЫЕ ПСИХОЛОГИЧЕСКИЕ ПОСЛЕДСТВИЯ ПАНДЕМИИ COVID-19 И ВОЙНЫ 2020 г. В АРМЕНИИ
}

Татевян Г. А. (Армянский государственный педагогический университет им. Х. Абовяна, Ереван, Армения) hrdatev@gmail.com

乙tipluјшgर्umu uर्u. 31.07.2021

9pmpunuर्जuद uर्जu. 12.08.2021

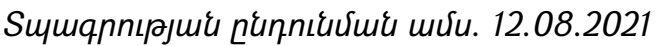

Представленное исследование посвящено психологическому воздействию COVID-19 и последней карабахской войны 2020г. на жителей Армении. В частности, представлены некоторые результаты исследования психологических последствий сочетанной психотравмы на представителей молодежи обеих полов. Особый интерес представляют полученные данные по уровню тревожности и экстраверсии. Исследовательская популяция включала заболевших и не заболевших коронавирусом и молодых людей, как участвовавших, так и не участвовавших в войне. Полученные результаты в известной степени отражают также особенности общего психологического состояния населения страны.

Ключевые слова: пандемия, война, психотравма, тревожность, посттравматические стрессовые расстройства.

DOI: https://doi.org/10.46991/SBMP/2021.4.2.343

Армения, как и другие страны мира, уже второй год живет в условиях пандемии, вызванной коронавирусом SARS-CoV-2. Пандемия, изменив привычный уклад жизни, оказала сильное влияние на все стороны жизнедеятельности и привела к определенным психологическим изменениям почти у всего населения страны. Однако данное воздействие и отношение людей к пандемии радикально менялось на протяжении этих полутора лет.

Изначальное несерьезное, а иногда просто наплевательское, отношение к ковиду, в частности - со стороны официальных лиц, у многих быстро сменилось на настороженное, а с первыми случаями смертей от ковида добавилось изрядное чувство страха. Введение карантина и переход работы на онлайн режим во многих сорерах деятельности еще больше увеличили стрессовое воздействие на людей. Однако очень скоро люди быстро начали адаптироваться к новой ситуации и постепенно, относительно более равнодушное отношение к ковиду снова стало преобладать у большинства.

Воздействия COVID-19 на людей разнообразны, начиная с соматических изменений, а именно: нарушения дыхательной, сердечно-сосудистой, 
желудочно-кишечной, нервной и иммунной систем, вызывающие тромбозы, аутоиммунные реакции и т.д, заканчивая неблагоприятными изменениями психической деятельности. Все это ставит задачи не только перед врачами, но и перед психологами. В этой связи в последнее время по всему миру было проведено огромное количество исследований, посвященных отдельным аспектам психологического воздействия COVID-19 на людей различных возрастов и полов, из отдельных социальных групп, имеющих различный образовательный ценз и уровень экономического достатка. В подтверждение сказанному, в качестве иллюстрации можно привести хотя бы исследование Л. Карстенстен, Й. Шавит и Дж. Бернс, посвященное эмоциональному состоянию и реагированию людей различных возрастных групп в условиях пандемии. [1]

Кроме вопросов, касающихся непосредственного воздействия ковида на психику, отдельного внимания заслуживают и вопросы отложенного влияния и долгосрочные последствия этого воздействия, которому отчасти посвящено наше исследование, проведенное в 2020-2021гг. Первоначальной целью исследования было изучить психологическое влияние на людей молодого возраста и оценить последствия отмеченного влияния и жизни людей, больше года живущих в условиях ковида. Однако, в первоначальные планы жизнь внесла свои коррективы, крайне неприятные и отрицательные. В сентябре 2020г. Азербайджан, игнорируя призыв Генерального секретаря ООН А. Гутереша от 23 марта 2020г. прекратить все вооруженные противоборства во время пандемии, развязал войну, продлившуюся 44 дня, ставшую причиной многотысячных жертв и появления более десяти тысяч раненых и ставших инвалидами, в первую очередь молодых ребят. Война ввергла народ в острейшую стрессовую ситуацию, а подписание 9-ого ноября договора между Арменией, Азербайджаном и Россией, означавшую фрактическую потерю Арцаха (Нагорного Карабаха) и капитуляцию Армении, стало дополнительной психотравмой для абсолютно подавляющей части населения. Люди оказались в ситуации сочетанной или комплексной психотравмы, когда стресс, связанный с войной, начал сильно превалировать над стрессом, вызванным пандемией. Следует отметить, что ранее подобная сочетанная психотравма имело место тридцать три года назад, когда на людей одновременно действовали землетрясение и погромы в Сумгаите, а затем - в Баку, предварившие начало первой карабахской войны.

Одновременное действие двух сильных стрессоров вообще, а в нашем случае - войны и ковида, усугубляет вредное воздействие на психику. Об этом говорят и другие специалисты: «Деструктивное совместное влияние смертоносной войны, гуманитарного кризиса, внутренней нестабильности и запредельный уровень скорости распространения вируса с высокой вероятностью приведут к кризису психического здоровья, требующему 
неотлагательного внимания. Все отмеченные вызовы и вспышка COVID-19 скорее всего вызовут первазивную тревожность у местного населения» [2, 2]. Такая ситуация мало изучена, и оценка последствий становится трудно прогнозируемой. В этой же работе делается ссылка на исследования К. Лейна и соавторов, изучавших психологические последствия войны в Боснии. И отмечается, что «... результаты воздействия одновременно и глобальной пандемии, и войны на психическое благополучие неизвестны, включая дополнительный и потенциально синергический эфффект этих двух констелляций стрессоров на психические расстройства» $[2,1]$.

Первоначальные планы нашего исследования при данных обстоятельствах, естественно, были скорректированы, так как в условиях сочетанной травмы выделить психологическое воздействие ковида в чистом виде стало практически невыполнимой задачей, и возникла необходимость использования дополнительных психометрических методик, а полученные результаты стали отражать комплексное психологическое состояние. С учетом этих изменений, исследование можно рассматривать в некотором смысле как пилотное, так как нужно было уточнить, какое сочетание психометрических методик наиболее функционально для изучения сочетанной психотравмы в ситуации, когда возникает задача деления влияния от различных стрессоров.

Для того, чтобы в какой-то мере попытаться выделить воздействие именно войны на психологическое состояние молодых людей, мы остановились на выборке, состоящей из 54 девушек (половина - переболевшие ковидом, а остальные - нет), 120 молодых ребят (половина - переболевшие ковидом, а остальные - нет), из которых 68 участвовали в войне. Была составлена специальная анкета, которая позволяла кроме демографических данных получить данные об отношении к ковиду, о потерях вследствие ковида и погибших среди близких людей. В качестве средств психометрических измерений были использованы следующие методики: для измерения уровня тревожности - Шкала тревожности Спилбергера, для общего описания личности - сокращенный вариант большой пятерки, - TIPI-10 [3], для определения целеполагания в жизни - тест Крамбо и Махолика [4], для измерения уровня посттравматического стрессового расстройства - Миннесотский опросник по ПТСР (военный и гражданский варианты). Исходя из параметров данной статьи, трудно подробно представить полученные результаты, однако хотелось бы остановиться на двух, представляющих определенный научный интерес.

Первое, данные, касающиеся вопросов тревожности. Тревожность часто сильно связана с общими стрессовыми и посттравматическими стрессовыми состояниями и является одним из главных зателей психологического неблагополучия. 
В многочисленных исследованиях, проведенных, в частности на американской, китайской и российской популяции, сообщалось об увеличении тревожных и депрессивных симптомов и частоты тревожно-депрессивных расстройств от умеренной до тяжелой степени. О повышенной тревожности и увеличении стрессовых расстройств у населения Армении говорится в статье С. Сукиасяна и соавторов, посвященной клинико-психопатологическим аспектам ковида [5]. Однако следует учесть, что эти исследования проводились в стадии активного распространения вируса. Данных же об отсроченных тревожных изменениях, по понятным причинам, в литературе трудно найти.

Исследуемых в нашем исследовании просили с помощью теста Спилбергера оценить свое состояние в данный момент и состояние в начале 2019г., до начала пандемии. Некоторые из полученных результатов представлены на приведенном ниже графике.

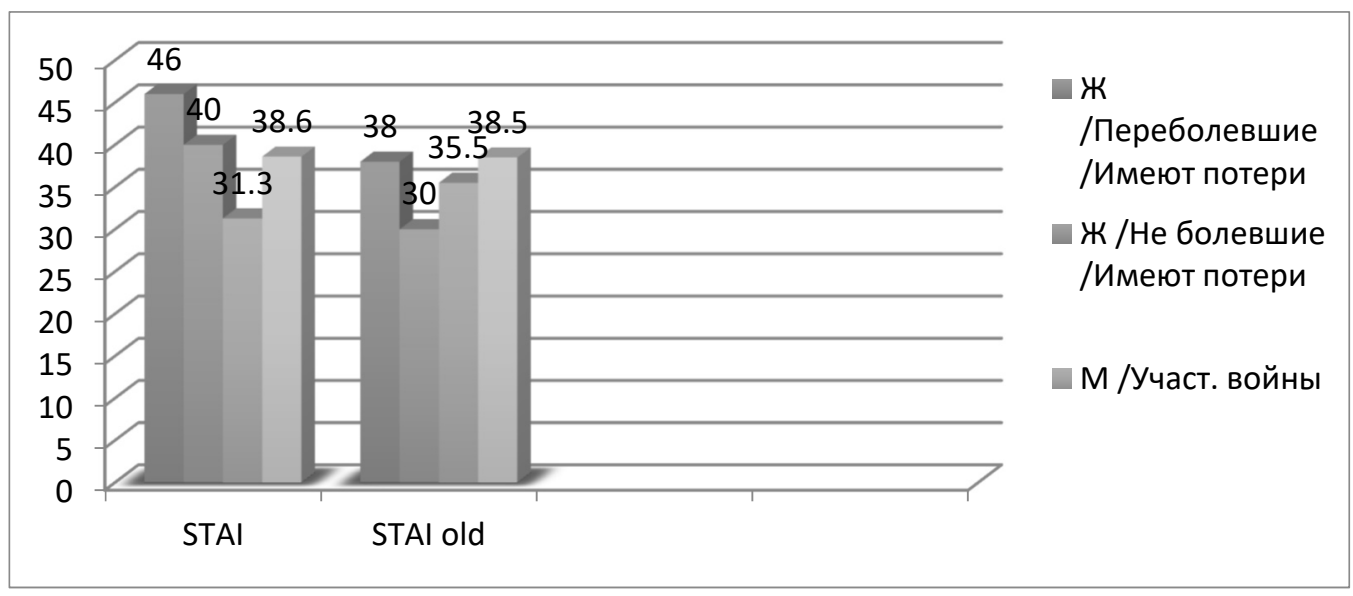

Как видно из рисунка, наибольшее изменение уровня тревожности по отношению к уровню 2019 г. наблюдается у девушек, имеющих личные потери, при чем у девушек, болевших ковидом, уровень тревожности выше, чем у не болевших. У молодых людей, участвовавших в войне, изменение уровня тревожности меньше. Как и ожидалось, тревожность у раненых выше, чем у тех, кто не получил ранения. Интересно, что у ребят, прошедших войну без ранений, тревожность даже снизилась по сравнению с довоенным и доковидным периодом. Последнее представляет особый интерес и требует дальнейших специальных исследований с целью более глубокого понимания влияния участия в войне на психологическое состояние людей.

Данные о посттравматическом стрессовом состоянии показывают умеренное (гораздо ниже ожидаемого) повышение, а какие впоследствии могут быть изменения, могут показать дальнейшие исследования. 
Другим, особо примечательным результатом являются данные, касающиеся экстравертивности-интравертивности исследуемой популяции. Даже учитывая определенно более высокую экстравертивность общей армянской популяции и, в частности, большую экстравертированность представителей женского пола, полученные результаты оказались неожиданными. При средних показателях в 5,1 (из максимум 6-и) у девушек и 4,6 у ребят, не участвовавших в войне, показатели 2,6 у участников войны вызывают по меньшей мере удивление, так как не может быть, что на войну уходили в основном интраверты. Вариантов объяснений не много: или участие в войне, постоянное нахождение в условиях риска для жизни и потери друзей так травмирует людей, делая их более замкнутыми (что в определенной степени согласуется с данными о ПТСР) и превращая экстравертов в интравертов, или стандартные психометрические методики, предназначенные для измерения экстравертивности, на самом деле измеряют нечто другое, связанное с глубинными, устойчивыми личностными структурами.

Приведенные выше результаты исследования заставляют по-новому интерпретировать некоторые устоявшиеся взгляды на многие психологические феномены и механизмы, и несомненно необходимы дальнейшие, глубинные исследования на большой выборке.

\section{Литература}

1. Carstensen L.L, Shavit Y.Z, and Barnes J.T. «Age Advantages in Emotional Experience Persist Even Under Treat From the COVID-19 Pandemic», Psychological Science - Volume 31 (11), 2020, pp. 1374-1385.

2. Markosian et al. "War in the COVID-19 era: Mental health concerns in Armenia and Nagorno-Karabakh». International Journal of Social Psychiatry, 1-3, 2021. pp.1-3.

3. Gosling, S. D., Rentfrow, P. J., \& Swann, W. B., Jr. (2003). A Very Brief Measure of the Big Five Personality Domains. Journal of Research in Personality, 37, pp. 504-528.

4. Crumbaugh, J. C., \& Maholick, L. T. (1969/1981). Manual of instructions for the purpose in life test. Abilene, TX: Viktor Frankl Institute of Logotherapy.

5. Сукиасян С.Г., Багдасарян Л.В., Согоян А.Ф., Григорян А.К. Клиникопсихопатологические аспекты эпидемии covid-19: результаты фейсбуковского опроса в Армении и Арцахе. /в печати/ 


\section{SOME PSYCHOLOGICAL CONSEQUENCES OF THE COVID-19 PANDEMIC AND THE WAR OF 2020 IN ARMENIA}

Tatevian H. A. (Armenian State Pedagogical University after Kh. Abovyan, Yerevan, Armenia)

The given study focuses on the psychological impact of COVID 19 and the latest Karabakh war in 2020 on the people of Armenia. In particular, some results of a study of the psychological consequences of combined psychological trauma on young people of both sexes are presented. The data obtained with regard to anxiety levels and extraversion are of particular interest. The study population included those who had been exposed or not to the coronavirus, as well as young people who had participated and those who hadn't participated in the war. The results obtained also reflect, to a certain extent, the peculiarities of the general psychological state of the country's population.

Keywords: COVID 19, War, Anxiety, Psychological Trauma, PTSD. 